\title{
Effect of fenofibrate on serum nitric oxide levels in patients with hypertriglyceridemia
}

\author{
Kerim Esenboga ${ }^{1, A, D, F}$, Ömer Faruk Çiçek ${ }^{2, C, F}$, Ahmet Afşin Oktay ${ }^{3, E, F}$, Pelin Aribal Ayral ${ }^{4, B, F}$, Adalet Gürlek ${ }^{5, E, F}$ \\ 1 Department of Cardiology, 29 Mayıs State Hospital, Ankara, Turkey \\ 2 Department of Cardiovascular Surgery, Selçuk University Faculty of Medicine, Konya, Turkey \\ ${ }^{3}$ Department of Cardiology, University of Queensland School of Medicine, Ochsner Medical Center, New Orleans, USA \\ ${ }^{4}$ Division of Pathophysiology, Department of Internal Medicine, Faculty of Medicine, Ankara University, Turkey \\ ${ }^{5}$ Department of Cardiology, Faculty of Medicine, Ankara University, Turkey \\ A - research concept and design; $\mathrm{B}$ - collection and/or assembly of data; $\mathrm{C}$ - data analysis and interpretation; \\ $D$ - writing the article; $E$ - critical revision of the article; $F$ - final approval of the article
}

\section{Address for correspondence \\ Kerim Esenboga}

E-mail: kerimesenboga@yahoo.com

\section{Funding sources}

Association of Turkish Clinical Vascular Biology

Conflict of interest

None declared

Received on August 6, 2017

Reviewed on September 16, 2017

Accepted on August 9, 2018

Published online on June 17, 2019

Cite as

Esenboga K, Çiçek ÖF, Oktay AA, Ayral PA, Gürlek A.

Effect of fenofibrate on serum nitric oxide levels in patients with hypertriglyceridemia. Adv Clin Exp Med. 2019;

28(7):931-936. doi:10.17219/acem94161

DOI

10.17219/acem/94161

\section{Copyright}

Copyright by Author(s)

This is an article distributed under the terms of the

Creative Commons Attribution Non-Commercial License

(http://creativecommons.org/licenses/by-nc-nd/4.0/)

\section{Abstract}

Background. Fenofibrate, a peroxisome proliferator-activated receptor-a (PPARa) agonist, is used to treat patients with hypercholesterolemia and hypertriglyceridemia in order to reduce the risk of development of the atherosclerotic cardiovascular disease. However, it exerts pleiotropic effects beyond correcting atherogenic dyslipidemia to treat hypercholesterolemia.

Objectives. The aim of this study was to investigate the potential effects of fenofibrate on endothelial function by analyzing the serum nitric oxide (NO) levels in patients with hypertriglyceridemia.

Material and methods. Lipid profiles and serum NO levels were assessed in 56 healthy adults aged 29 to 84 years, before and after 12 weeks of fenofibrate $(250 \mathrm{mg} / \mathrm{d} ; \mathrm{n}=30)$ or placebo $(\mathrm{n}=26)$. Appropriate dietary suggestions for hypertriglyceridemia were made for all patients. This study was randomized, doubleblind and placebo-controlled in design.

Results. Total cholesterol, low-density lipoprotein (LDL), very low-density lipoprotein (VLDL) and triglyceride levels significantly decreased; high-density lipoprotein (HDL) and NO levels significantly increased after 12 weeks of fenofibrate therapy. We observed a statistically significant correlation between the increase in serum NO levels and decrease in serum triglyceride levels $(r=-0.42, p=0.02)$ in the fenofibrate group.

Conclusions. The positive effect of short-term fenofibrate treatments on vascular endothelial functions in patients with hypertriglyceridemia has been demonstrated by increasing the serum NO levels. Agents such as fenofibrate targeting PPARa-associated signaling pathways show promise as an alternative treatment of vascular dysfunction related to advanced age and hyperlipidemia.

Key words: fibrate, hypertriglyceridemia, nitric oxide 


\section{Introduction}

The endothelium plays a major role in not only regulation of the function but also the protection of the normal structure of vascular tissue mainly by the production of nitric oxide (NO). Endothelium-derived NO is a strong endogenous vasodilator, acting through the activation of the soluble guanylate cyclase resulting in cyclic guanosine monophosphate (cGMP) production. ${ }^{1-3}$ Nitric oxide takes a role in regulating vascular tone; on the other hand, some important steps, such as smooth muscle proliferation in vascular tissue, platelet accumulation and endothelial cell-leukocyte interaction in the development of atherosclerosis and thrombosis, are also inhibited by NO. ${ }^{4-9}$ The presence of cardiovascular risk factors may lead to impaired endothelial integrity as a result of decreased levels of NO released from endothelium. ${ }^{10}$ Hypercholesterolemia, an important cause of atherosclerosis formation and progression, also results in decreased vascular NO activity. ${ }^{11,12}$

In animal studies, the inhibition of NO synthesis in hypercholesterolemia gives rise to the progression of development of atherosclerosis, while the increase in NO levels slows down or even regresses it. ${ }^{13-16}$ The mechanism underlying the impairment of endothelial NO syntheses by hypercholesterolemia has remained unclear; however, it is essential to define new treatment modalities for improving vascular endothelial function by increasing vascular NO activity in patients with hyperlipidemia.

Fenofibrate, a peroxisome proliferator-activated receptor (PPAR)- $\alpha$ agonist, exerts several pleiotropic effects beyond treating atherogenic dyslipidemia by lowering plasma triacylglycerides and consequently modifying the morphology of low-density lipoprotein (LDL) and high-density lipoprotein (HDL) particles. Fatty acids and derivatives activate the PPAR nuclear receptors. In experimental studies, it has been demonstrated that PPAR- $\alpha$ receptor activation plays an important role in all stages of the development of atherosclerosis such as vascular inflammation, suggesting that the antiatherogenic actions of PPAR- $\alpha$ occur at the level of the vascular wall. ${ }^{17}$ Fenofibrate improves endothelium-dependent dilation (EDD) in the microcirculation (i.e., small mesenteric arteries) in old rats, and increases brachial artery flow-mediated dilatation (FMD) in patients with type 2 diabetes mellitus. ${ }^{18,19}$ Impairment of the NO synthase (NOS) pathway contributes to the inhibition of EDD. ${ }^{20}$ Fenofibrate induces an increase in endothelial NOS expression in humans, as well as in cultured endothelial cells and the aorta of rats. ${ }^{21-23}$ However, plasma levels of malondialdehyde and nitrate in humans were not changed by therapy with fenofibrate. ${ }^{24}$

The objective of this study was to investigate the effect of fenofibrate therapy on serum NO level in hypertriglyceridemia.

\section{Material and methods}

\section{Subjects and study design}

The Ethics Committee of the Ankara University Faculty of Medicine approved the study and all procedures were carried out according to the Declaration of Helsinki. All participants gave written informed consent. The study was funded by the Association of Turkish Clinical Vascular Biology.

This study was randomized, prospective and placebo-controlled in design. Sixty-eight hypertriglyceridemic patients who were admitted to our outpatient clinic in the Cardiology Department of the Ankara University School of Medicine between February 2014 and February 2015 were evaluated to enroll in the study. A total of 8 patients, of whom 3 patients declined to participate the study and 5 patients did not meet the inclusion criteria, were excluded from the study. The study population consisted of 60 patients who were allocated to the 2 arms (Fig. 1). The exclusion criteria included known vascular disease, stable angina pectoris, smoking, serum creatinine $>1.5 \mathrm{mg} / \mathrm{dL}$, abnormal liver or muscle enzymes, alcohol consumption, or use of antioxidant or lipid-regulating therapy. The past medical history of all participants was examined in detail and 12-lead electrocardiography, and a physical examination with measurement of liver enzymes, renal function test, fasting lipid profile, and glucose were performed. Sixty patients were randomly assigned to receive either oral treatment with 250-mg micronized fenofibrate $(n=30)$ or placebo capsules $(n=30)$ once daily for 12 weeks. A computer-generated table of random numbers (1:1) was used for accurate randomization. Four patients in the placebo group dropped out of treatment on their own decision during the study after randomization, so 26 patients reached the final analyses in the placebo group. Both investigators and patients were blinded to the treatment. A physician was assigned to count the pills to assess treatment compliance. Minor adverse effects that did not require drug withdrawal, such as abdominal pain in 2 patients, dyspepsia in 1 patient, and dizziness in 1 patient, were observed in the treatment group during the follow-up period. In our study, appropriate dietary suggestions for hypertriglyceridemia were made for all patients with no objective follow-up of participants' compliance with diet.

\section{Laboratory assays}

Venous blood samples were taken in the morning after overnight fasting to study the biochemical parameters at the beginning and at the end of both treatment periods.

It is recommended that patients take fenofibrate treatment with their evening meal. Patients were reviewed every 2 weeks to assess compliance with the treatment, adverse effects, body weight, and blood pressure. Plasma liver and muscle enzymes were monitored at 6-week intervals. 
CONSORT Flow Diagram

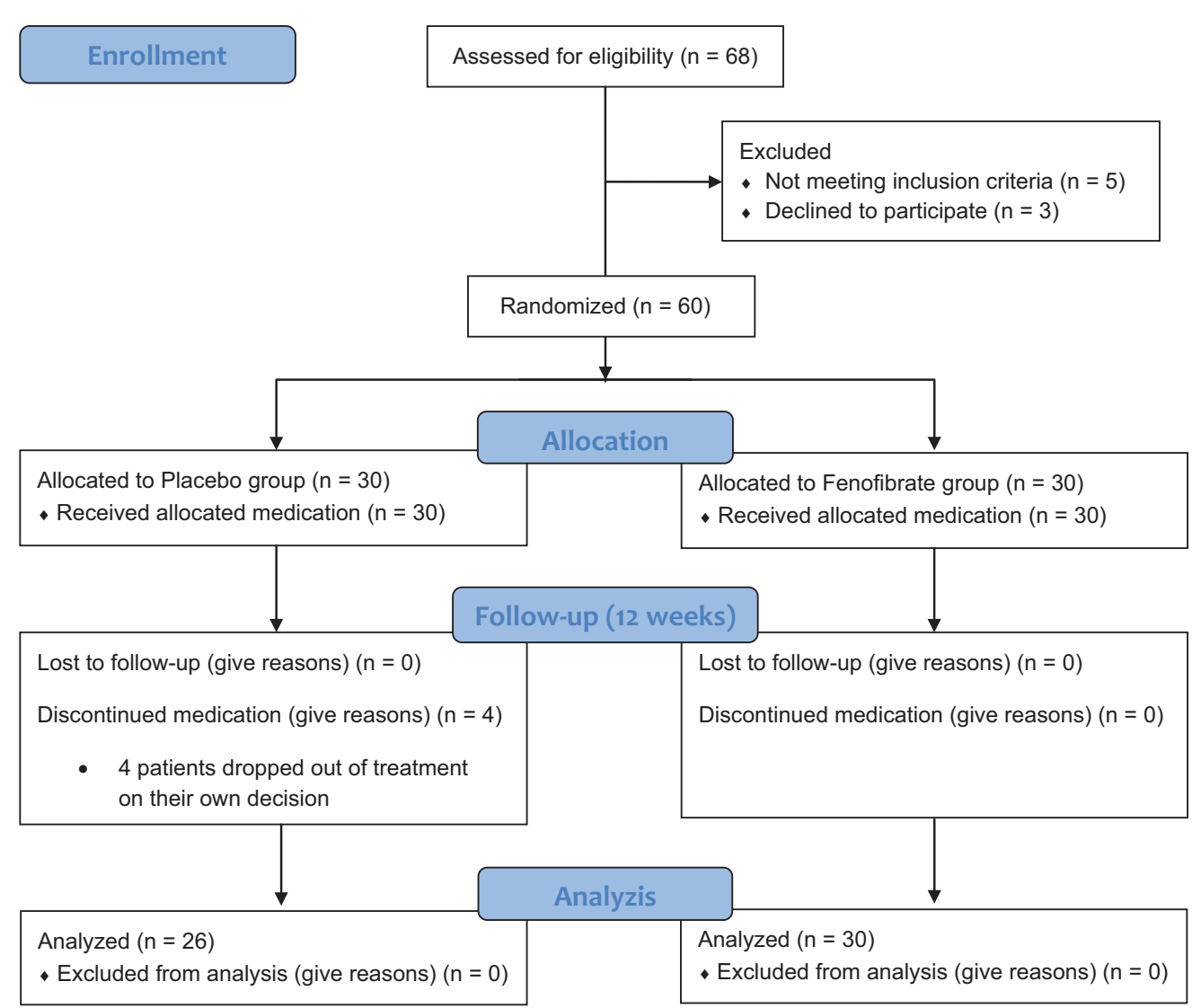

Fig. 1. Consolidated Standards of Reporting Trials (CONSORT) flow diagram of patients enrolled in the study
Fasting triglyceride, HDL cholesterol and total cholesterol were examined using enzymatic kits (Roche Diagnostics, Risch-Rotkreuz, Switzerland), and LDL-cholesterol was calculated using the Friedewald formula. Serum creatinine and CK were measured using Roche Diagnostics reagents and a Hitachi 917 analyzer (Hitachi Ltd., Tokyo, Japan).

For the vast majority of convenient methods, it is impossible to detect NO because of its volatile and transient character. However, as a result of $\mathrm{NO}$ oxidizing to nitrite (NO2-) and nitrate (NO3-), we used these anions' concentrations as a quantitative measurement of NO production. We performed the spectrophotometric measurement of NO2- by performing the Griess reaction after the conversion of NO3 - to NO2-. Nitric oxide can be determined with this assay, which is achieved by nitrate reductase activity converting nitrate to nitrite. After the reaction, the nitrite is detected with colorimetric methods as an azo dye product of the Griess reaction. Nitric oxide concentration is indirectly measured by identifying both nitrite and nitrate levels in the specimen.

\section{Statistical analysis}

We analyzed the data with the Statistical Package for the Social Sciences (SPSS) v. 20.0 for Windows (IBM Corp., Armonk, USA). Categorical variables were summarized as percentages; continuous variables are presented as mean \pm standard deviation (SD) or median with interquartile range according to normal distribution. The data was analyzed with the Shapiro-Wilk test for normal distribution. Groups were compared with $\chi^{2}$ tests with Yates's correction or Fisher's exact test for categorical variables and the independent sample t-test or Mann-Whitney $\mathrm{U}$ test according to the distribution of data for continuous variables. Pre- and post-treatment parameters were compared using paired sample t-test for normally distributed variables, and the Wilcoxon signed rank test was used for non-normally distributed variables. Changes in serum NO levels and the changes in blood lipid parameters were distributed normally, therefore the Pearson test was used to analyze correlations. A value of $\mathrm{p}<0.05$ was considered statistically significant.

\section{Results}

A comparison of patients with placebo $(\mathrm{n}=26 ; 10$ male and 16 female; mean age $53.5 \pm 15.1$ years) and those with fenofibrate therapy $(\mathrm{n}=30 ; 8$ male and 22 female; mean age $55.7 \pm 7$ years) regarding baseline characteristics and laboratory findings is demonstrated in Table 1 . No significant differences were detected between the 2 groups in terms of sex, age, the presence of hypertension, diabetes mellitus, hypothyroidism, chronic obstructive pulmonary 
Table 1. Baseline characteristics of the study and control group

\begin{tabular}{|c|c|c|c|}
\hline Variable & $\begin{array}{l}\text { Placebo } \\
(n=26)\end{array}$ & $\begin{array}{l}\text { Fenofibrate } \\
\qquad(\mathrm{n}=30)\end{array}$ & $p$-value \\
\hline Age, years & $53.5 \pm 15.1$ & $55.7 \pm 7$ & 0.19 \\
\hline Male gender, n (\%) & $10(38.5)$ & $8(26.7)$ & 0.5 \\
\hline Hypertension, n (\%) & $18(69.2)$ & $26(86.7)$ & 0.21 \\
\hline Diabetes mellitus, n (\%) & $6(23.1)$ & $10(33.3)$ & 0.58 \\
\hline Hypothyroidism, n (\%) & $2(7.7)$ & - & 0.21 \\
\hline COPD, n (\%) & $1(3.8)$ & $3(10)$ & 0.6 \\
\hline ACE-I or ARB use, $n(\%)$ & $16(61.5)$ & $24(80)$ & 0.22 \\
\hline$\beta$-blocker use, n (\%) & $6(23.1)$ & $6(20)$ & 1 \\
\hline Diuretics use, n (\%) & $2(7.7)$ & $2(6.7)$ & 1 \\
\hline $\begin{array}{l}\text { Calcium channel } \\
\text { blockers use, n (\%) }\end{array}$ & - & $2(6.7)$ & 0.49 \\
\hline $\begin{array}{l}\text { Total cholesterol } \\
{[\mathrm{mg} / \mathrm{dL}]}\end{array}$ & $217.1 \pm 28.4$ & $238.3 \pm 52.8$ & 0.09 \\
\hline $\begin{array}{l}\text { LDL cholesterol } \\
{[\mathrm{mg} / \mathrm{dL}]}\end{array}$ & $127.5 \pm 22.5$ & $141.2 \pm 30$ & 0.08 \\
\hline $\begin{array}{l}\text { HDL cholesterol } \\
{[\mathrm{mg} / \mathrm{dL}]}\end{array}$ & $39.9 \pm 8$ & $40.6 \pm 10.7$ & 0.81 \\
\hline VLDL [mg/dL] & $52(36-55)$ & $68.7(46-77)$ & 0.07 \\
\hline Triglycerides [mg/dL] & $330 \pm 25.4$ & $380.9 \pm 139.4$ & 0.12 \\
\hline $\mathrm{NO}[\mu \mathrm{M}]$ & $26.4 \pm 11.9$ & $30.9 \pm 12.4$ & 0.17 \\
\hline Creatinine $[\mathrm{mg} / \mathrm{dL}]$ & $0.74(0.65-0.92)$ & $0.83(0.68-0.98)$ & 0.5 \\
\hline Creatinine kinase $[\mathrm{u} / \mathrm{L}]$ & $128(79-250)$ & $85.5(62.75-160.75)$ & 0.39 \\
\hline Adverse effect, n (\%) & - & $4(13.3)$ & 0.12 \\
\hline
\end{tabular}

COPD - chronic obstructive pumonary disease; VLDL - very low-density lipoprotein; LDL - low-density lipoprotein; HDL - high-density lipoprotein; $\mathrm{NO}$ - nitric oxide.

disease (COPD), cardiovascular drug use, blood lipid panel, and NO level.

Biochemical measurements recorded at baseline and after 12 weeks of fenofibrate or placebo are listed in Table 2. Baseline triglyceride levels decreased significantly after 12 weeks in the placebo group ( $\mathrm{p}<0.001$ ); however, there was no significant change in other types of blood lipid parameters and NO level. Total cholesterol, LDL, very low-density lipoprotein (VLDL) and triglyceride levels significantly decreased; HDL and NO levels significantly increased after 12 weeks of fenofibrate therapy. Treatment with fenofibrate

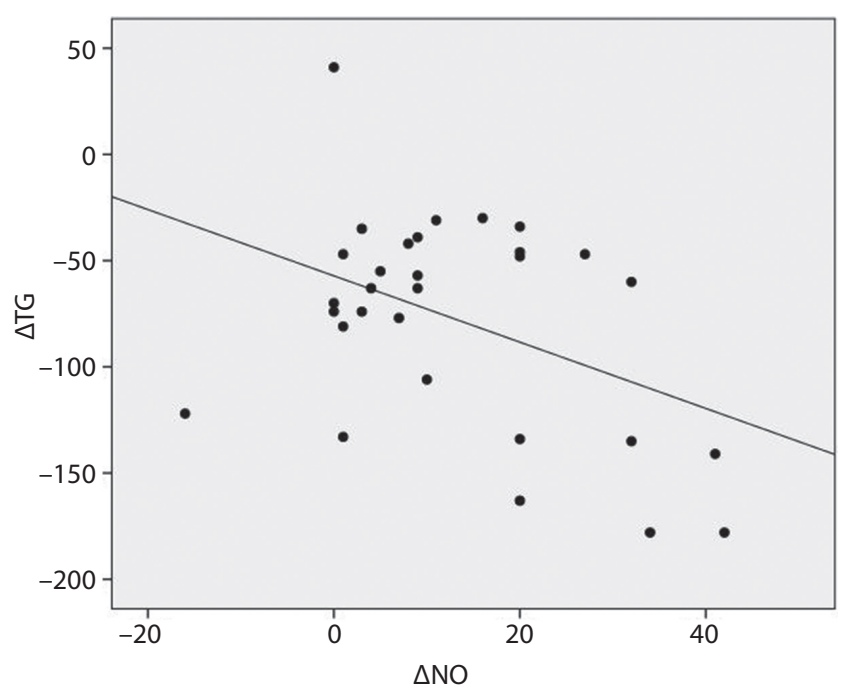

Fig. 2. Statistically significant correlation between the increase in serum $\mathrm{NO}$ levels and decrease in serum triglyceride levels $(r=-0.42, p=0.02)$.

( $\triangle \mathrm{NO}$ : change in serum $\mathrm{NO}$ levels; $\triangle \mathrm{TG}$ : change in serum triglyceride levels)

resulted in a significant increase in serum NO levels compared to the placebo group ( $\mathrm{p}<0.001$ vs $\mathrm{p}=0.06$ ).

Table 3 compares the magnitude of both groups' various parameter changes during the study. This comparison revealed that the increase in HDL and creatinine, and the decrease in creatinine kinase, are similar in the placebo and fenofibrate groups, but that the decreases in total cholesterol, LDL, VLDL and triglycerides, and the increase in $\mathrm{NO}$, are significantly higher in the fenofibrate group.

We observed a statistically significant correlation between the increase in serum NO levels and decrease in serum triglyceride levels $(r=-0.42, p=0.02$; Fig. 2), with a non-significant correlation for other changes in the lipid variables (HDL: $\mathrm{r}=0.04, \mathrm{p}=0.84 ; \mathrm{VLDL}: \mathrm{r}=0.12, \mathrm{p}=0.55$; total cholesterol: $\mathrm{r}=0.35, \mathrm{p}=0.07$; and LDL $\mathrm{r}=0.03$, $\mathrm{p}=0.87$; Table 4) in the fenofibrate group.

\section{Discussion}

In our study, it has been demonstrated that fenofibrate significantly decreased total cholesterol, LDL cholesterol, VLDL cholesterol and triglycerides, and increased HDL

Table 2. Biochemical variables at baseline and 12 weeks for placebo and fenofibrate groups

\begin{tabular}{|c|c|c|c|c|c|c|}
\hline \multirow{2}{*}{ Variables } & \multicolumn{3}{|c|}{ Placebo group } & \multicolumn{3}{|c|}{ Fenofibrate group } \\
\hline & baseline & $12^{\text {th }}$ week & $p$-value & baseline & $12^{\text {th }}$ week & $p$-value \\
\hline Total cholesterol [mg/dL] & $217.1 \pm 28.4$ & $213 \pm 36.3$ & 0.3 & $238.3 \pm 52.8$ & $186.7 \pm 36.6$ & $p<0.001$ \\
\hline LDL cholesterol [mg/dL] & $127.5 \pm 22.5$ & $123.2 \pm 22.9$ & 0.07 & $141.2 \pm 30$ & $106.8 \pm 33.5$ & $p<0.001$ \\
\hline HDL cholesterol [mg/dL] & $39.9 \pm 8$ & $41.9 \pm 7.8$ & 0.15 & $40.6 \pm 10.7$ & $43.5 \pm 8.6$ & 0.001 \\
\hline VLDL [mg/dL] & $52(36-55)$ & $35(30-54)$ & 0.89 & $68.7(46-77)$ & $38(31-56)$ & 0.001 \\
\hline Triglycerides [mg/dL] & $330 \pm 25.4$ & $280.4 \pm 38.9$ & $p<0.001$ & $380.9 \pm 139.4$ & $303.5 \pm 120$ & $p<0.001$ \\
\hline Nitric oxide $[\mu \mathrm{M}]$ & $26.4 \pm 11.9$ & $27.1 \pm 12.4$ & 0.06 & $30.9 \pm 12.4$ & $43.9 \pm 15.8$ & $p<0.001$ \\
\hline
\end{tabular}

VLDL - very low-density lipoprotein; LDL - low-density lipoprotein; HDL - high-density lipoprotein. 
Table 3. Comparison of the magnitude of the changes from baseline to $12^{\text {th }}$ week follow-up evaluation in placebo and fenofibrate groups

\begin{tabular}{|c|c|c|c|}
\hline Variables & $\begin{array}{l}\text { Change } \\
\text { in placebo } \\
\text { group after } \\
12 \text { weeks } \\
(n=26)\end{array}$ & $\begin{array}{l}\text { Change } \\
\text { in fenofibrate } \\
\text { group after } \\
12 \text { weeks } \\
(\mathrm{n}=30)\end{array}$ & p-value \\
\hline $\begin{array}{l}\text { Total cholesterol } \\
{[\mathrm{mg} / \mathrm{dL}]}\end{array}$ & $-14.5 \pm 50.1$ & $-51.6 \pm 45.1$ & 0.02 \\
\hline $\begin{array}{l}\text { LDL cholesterol } \\
{[\mathrm{mg} / \mathrm{dL}]}\end{array}$ & $-4.3 \pm 10.9$ & $-34.3 \pm 30.3$ & $p<0.001$ \\
\hline $\begin{array}{l}\text { HDL cholesterol } \\
{[\mathrm{mg} / \mathrm{dL}]}\end{array}$ & $2 \pm 6.2$ & $2.9 \pm 4.3$ & 0.53 \\
\hline VLDL [mg/dL] & $-0.5 \pm 13.1$ & $-33.9 \pm 47.2$ & 0.01 \\
\hline Triglycerides [mg/dL] & $-49.6 \pm 26.5$ & $-77.4 \pm 50.6$ & 0.01 \\
\hline Creatinine $[\mathrm{mg} / \mathrm{dL}]$ & $0.03 \pm 0.14$ & $0.03 \pm 0.09$ & 0.87 \\
\hline Creatinine kinase $[\mathrm{u} / \mathrm{L}]$ & $-16.7 \pm 7.4$ & $-10.3 \pm 18.4$ & 0.44 \\
\hline Nitric oxide $[\mu \mathrm{M}]$ & $0.77 \pm 1.9$ & $12.9 \pm 13.7$ & $p<0.001$ \\
\hline
\end{tabular}

VLDL - very low-density lipoprotein; LDL - low-density lipoprotein; $\mathrm{HDL}$ - high-density lipoprotein.

Table 4. Correlation between changes in serum NO levels and changes in blood lipid parameters in the fenofibrate group

\begin{tabular}{|l|c|c|}
\multirow{2}{*}{\multicolumn{1}{c|}{ Variables }} & \multicolumn{2}{|c|}{$\Delta$ NO level } \\
\cline { 2 - 3 } & $r$ & $p$-value \\
\hline$\triangle$ Triglycerides & -0.42 & 0.02 \\
\hline$\triangle \mathrm{VLDL}$ & 0.12 & 0.55 \\
\hline$\triangle \mathrm{HDL}$ & 0.04 & 0.84 \\
\hline $\mathrm{LDL}$ & 0.03 & 0.87 \\
\hline$\triangle$ Total cholesterol & 0.35 & 0.07 \\
\hline
\end{tabular}

r - correlation coefficient; VLDL - very low-density lipoprotein; LDL - lowdensity lipoprotein; HDL - high-density lipoprotein; NO - nitric oxide.

in patients with hypertriglyceridemia. Besides being a hypolipidemic drug, there are some important molecular and metabolic pleiotropic effects of fenofibrate on the vascular endothelium. Previous studies have demonstrated the effect of fibrates on vasomotor function as a pleiotropic effect on vascular endothelium. It has been shown that 12 weeks of fenofibrate therapy improves FMD in patients with type 2 diabetes mellitus after oral fat loading. ${ }^{25}$ On the other hand, 3 weeks of gemfibrozil therapy did not show similar beneficial effects in healthy volunteers. ${ }^{26}$ When compared with a placebo, bezafibrate therapy increases coronary artery dilation after exercise in patients with coronary artery disease; however, FMD was not changed significantly by either gemfibrozil usage alone or combination therapy with niacin. ${ }^{27,28}$ Endotheliumdependent dilation in patients with hyperlipidemia and type 2 diabetes mellitus as well as in healthy middle-aged and older normolipidemic individuals were improved by therapy with fenofibrate. . $^{1921,24,29-32}$

Although the results were controversial, it was observed in most of the studies that fenofibrate therapy significantly improves FMD. It is plausible that the hypolipidemic action of fenofibrate may account for this pleiotropic effect. From this hypothesis, it can be proposed that there was a significant correlation between the alteration in lipid levels and amelioration in FMD. On the other hand, it was also reported that improvements in EDD with fenofibrate was independent of reductions in lipids. ${ }^{21,32}$ In these patients, improvements in EDD were provided by the increased activity of endothelial NOS, which plays a major role in ensuring NO release from vascular endothelial cells in healthy humans. ${ }^{21}$ In another clinical trial, it was also shown that treatment with fenofibrate in patients with metabolic syndrome improved the endothelial protective effects of HDL by demonstrating the advanced ability of HDL to induce the expression of endothelial NOS on human umbilical vein endothelial cells. ${ }^{33}$ Furthermore, PPAR- $\alpha$ agonists induced production of endothelial NOS in cell cultures, which leads to decreased oxidative stress, with increased bioactivity of NO. ${ }^{22,34}$ Naturally occurring PPAR agonists can impede the inducible NOS enzyme pathway. Thus, the production of eicosanoid breakdown products as a result of inflammation may assist in its eventual resolution by activation of the PPAR pathway. In addition to these anti-inflammatory effects, PPAR- $\alpha$ ligands may improve endothelial NOS activity. ${ }^{35}$ The activation of PPAR- $\alpha$ by fenofibrate in mice not only improved endothelial vasodilatation but also prevented myocardial ischemic injury, so treatment with fenofibrate ameliorated post-ischemic contractile dysfunction and decreased myocardial infarct size by an antioxidant mechanism that enhanced the bioavailability of NO. ${ }^{36}$ Similarly, cardioprotection in a rat model of diabetic and acute myocardial infarction is also generated by fenofibrate + metformin combination therapy and fenofibrate therapy alone via decreased inducible NOS (iNOS) activity and increased NO bioavailability. ${ }^{37}$ Additionally, fenofibrate therapy remained significantly associated with increased NO production and decreased serum asymmetric dimethylarginine level, leading to amelioration of inflammation and oxidation in rats. ${ }^{38}$ However, the plasma levels of malondialdehyde and nitrate in humans were not changed by therapy with fenofibrate. ${ }^{24}$

Most of the studies showed that fenofibrate therapy significantly improved FMD, whereas serum NO levels were not measured in participants, so it had not been investigated whether there was a correlation between improved FMD and change in serum NO levels. In the literature, there was only 1 study which showed that fenofibrate therapy did not alter plasma levels of malondialdehyde and nitrate in humans, despite a significant improvement in FMD. ${ }^{24}$ Thus, it is claimed that fenofibrate may not have clinically important antioxidant effects. Here, we demonstrate for the first time that compared with placebo, fenofibrate significantly increases the serum NO levels in patients with hypertriglyceridemia. These results indicate that fenofibrate targeting the PPAR $\alpha$-related signaling pathways shows promise for the treatment of vascular dysfunction associated with dyslipidemic status including hypertriglyceridemia, and the prevention of cardiovascular disease. 
On limitation is this result is not supported by any clinical test such as FMD, etc. demonstrating the relationship between improved endothelial function and increased serum NO levels as a pleiotropic effect of fenofibrate. Additionally, the small patient population is another limitation of this study.

In conclusion, fenofibrate significantly changes lipoprotein levels by decreasing total cholesterol, LDL cholesterol, VLDL cholesterol and triglycerides, and increasing HDL-C. It also significantly increases the serum NO levels in patients with hypertriglyceridemia as a pleiotropic effect.

\section{References}

1. Furchgott RF, Zawadzki JV. The obligatory role of endothelial cells in the relaxation of arterial smooth muscle by acetylcholine. Nature. 1980;288(5789):373-376.

2. Murad F. The 1996 Albert Lasker Medical Research Awards: Signal transduction using nitric oxide and cyclic guanosine monophosphate. JAMA. 1996;276(14):1189-1192.

3. Palmer RMJ, Ferrige AG, Moncada S. Nitric oxide accounts for the biological activity of endothelium-derived relaxing factor. Nature. 1987; 327(6122):524-526.

4. Garg UC, Hassid A. Nitric oxide-generating vasodilators and 8-bromocyclic guanosine monophosphate inhibit mitogenesis and proliferation of cultured rat vascular smooth muscle cells. J Clin Invest. 1989:83(5):1774-1777.

5. von der Leyen HE, Gibbons GH, Morishita R, et al. Gene therapy inhibiting neointimal vascular lesion: In vivo transfer of endothelial cell nitric oxide synthase gene. Proc Natl Acad Sci USA. 1995;92(4):1137-1141.

6. Stamler J, Mendelsohn ME, Amarante P, et al. N-Acetylcysteine potentiates platelet inhibition by endothelium-derived relaxing factor. Circ Res. 1989;65(3):789-795.

7. Radomski MW, Palmer RMJ, Moncada S. Endogenous nitric oxide inhibits human platelet adhesion to vascular endothelium. Lancet. 1987;2(8567):1057-1058.

8. Bath PMW, Hassal DG, Gladwin AM, Palmer RM, Martin JF. Nitric oxide and prostacyclin: Divergence of inhibitory effects on monocyte chemotaxis and adhesion to endothelium in vitro. Arterioscler Thromb. 1991;11(2):254-260.

9. Kubes P, Suzuki M, Granger DN. Nitric oxide: An endogenous modulator of leukocyte adhesion. Proc Natl Acad Sci USA. 1991;88(11):4651-4655.

10. Vincent MA, Montagnani M, Quon MJ. Molecular and physiologic actions of insulin related to production of nitric oxide in vascular endothelium. Curr Diab Rep. 2003;3(4):279-288.

11. Creager MA, Cooke JP, Mendelsohn ME, et al. Impaired vasodilation of forearm resistance vessels in hypercholesterolemic humans. J Clin Invest. 1990;86(1):228-234.

12. Wolf A, Zalpour C, Theilmeier $G$, et al. Dietary L-arginine supplementation normalizes platelet aggregation in hypercholesterolemic humans. J Am Coll Cardiol. 1997;29(3):479-485.

13. Cooke JP, Singer AH, Tsao P, Zera P, Rowan RA, Billingham ME. Antiatherosclerotic effects of $\mathrm{L}$-arginine in the hypercholesterolemic rabbit. J Clin Invest. 1992;90(3):1168-1172.

14. Tsao PS, McEvoy LM, Drexler H, Butcher EC, Cooke JP. Enhanced endothelial adhesiveness in hypercholesterolemia is attenuated by L-arginine. Circulation. 1994;89(5):2176-2182.

15. Cayatte AJ, Palacino JJ, Horten K, Cohen RA. Chronic inhibition of nitric oxide production accelerates neointima formation and impairs endothelial function in hypercholesterolemic rabbits. Arterioscler Thromb. 1994;14(5):753-759.

16. Candipan RC, Wang BY, Buitrago R, Tsao PS, Cooke JP. Regression or progression: Dependency on vascular nitric oxide. Arterioscler Thromb Vasc Biol. 1996;16(1):44-50.

17. Barbier O, Torra IP, Duguay Y, et al. Pleiotropic actions of peroxisome proliferator activated receptors in lipid metabolism and atherosclerosis. Arterioscler Thromb Vasc Biol. 2002;22(5):717-726.

18. Alvarez de Sotomayor M, Mingorance C, Andriantsitohaina R. Fenofibrate improves age-related endothelial dysfunction in rat resistance arteries. Atherosclerosis. 2007;193(1):112-120.
19. Playford DA, Watts GF, Best JD, Burke V. Effect of fenofibrate on brachial artery flow-mediated dilatation in type 2 diabetes mellitus. Am J Cardiol. 2002;90(11):1254-1257.

20. Taddei S, Virdis A, Ghiadoni L, et al. Age-related reduction of NO availability and oxidative stress in humans. Hypertension. 2001;38(2): 274-279.

21. Walker AE, Kaplon RE, Lucking SM, Russell-Nowlan MJ, Eckel RH, Seals DR. Fenofibrate improves vascular endothelial function by reducing oxidative stress while increasing endothelial nitric oxide synthase in healthy normolipidemic older adults. Hypertension. 2012;60(6): 1517-1523.

22. Goya K, Sumitani S, Xu X, et al. Peroxisome proliferator-activated receptor a agonists increase nitric oxide synthase expression in vascular endothelial cells. Arterioscler Thromb Vasc Biol. 2004;24(4): 658-663.

23. Blanco-Rivero J, Márquez-Rodas I, Xavier FE, et al. Long-term fenofibrate treatment impairs endothelium-dependent dilation to acetylcholine by altering the cyclooxygenase pathway. Cardiovasc Res. 2007;7592):398-407.

24. Kon Koh K, Yeal Ahn J, Hwan Han S, et al. Effects of fenofibrate on lipoproteins, vasomotor function, and serological markers of inflammation, plaque stabilization, and hemostasis. Atherosclerosis. 2004; 174(2):379-383.

25. Evans M, Anderson RA, Graham J, et al. Ciprofibrate therapy improves endothelial function and reduces postprandial lipemia and oxidative stress in type 2 diabetes mellitus. Circulation. 2000;101:1773-1779.

26. Wilmink HW, Twickler MB, Banga JD, et al. Effect of statin versus fibrate on postprandial endothelial dysfunction: Role of remnantlike particles. Cardiovasc Res. 2001;50(3):577-582.

27. Seiler C, Suter TM, Hess OM. Exercise-induced vasomotion of angiographically normal and stenotic coronary arteries improves after cholesterol-lowering drug therapy with bezafibrate. J Am Coll Cardiol. 1995;26(7):1615-1622.

28. Andrews TC, Whitney EJ, Green G, Kalenian R, Personius BE. Effect of gemfibrozil +/- niacin +/- cholestyramine on endothelial function in patients with serum low-density lipoprotein cholesterol levels $<160 \mathrm{mg} / \mathrm{dL}$ and high-density lipoprotein cholesterol levels $<40 \mathrm{mg} / \mathrm{dL}$. Am J Cardiol. 1997;80(7):831-835.

29. Hamilton SJ, Chew GT, Davis TM, Watts GF. Fenofibrate improves endothelial function in the brachial artery and forearm resistance arterioles of statin-treated type 2 diabetic patients. Clin Sci (Lond). 2010;118(10):607-615.

30. Capell WH, DeSouza CA, Poirier P, et al. Short-term triglyceride lowering with fenofibrate improves vasodilator function in subjects with hypertriglyceridemia. Arterioscler Thromb Vasc Biol. 2003;23(2):307-313.

31. Koh KK, Han SH, Quon MJ, Yeal Ahn J, Shin EK. Beneficial effects of fenofibrate to improve endothelial dysfunction and raise adiponectin levels in patients with primary hypertriglyceridemia. Diabetes Care. 2005;28(6):1419-1424.

32. Malik J, Melenovsky V, Wichterle D, et al. Both fenofibrate and atorvastatin improve vascular reactivity in combined hyperlipidaemia (fenofibrate versus atorvastatin trial-FAT). Cardiovasc Res. 2001;52(2): 290-298.

33. Gomaraschi M, Ossoli A, Adorni MP, et al. Fenofibrate and extendedrelease niacin improve the endothelial protective effects of $H D L$ in patients with metabolic syndrome. Vascul Pharmacol. 2015;74:80-86.

34. Diep QN, Amiri F, Touyz RM, et al. PPAR- activator effects on Ang IIinduced vascular oxidative stress and inflammation. Hypertension. 2002;40:866-871.

35. Colville-Nash PR, Qureshi SS, Willis D, Willoughby DA. Inhibition of inducible nitric oxide synthase by peroxisome proliferator-activated receptor agonists: Correlation with induction of heme oxygenase 1. J Immunol. 1998;161(2):978-984.

36. Tabernero A, Schoonjans K, Jesel L, Carpusca I, Auwerx J, Andriantsitohaina R. Activation of the peroxisome proliferator-activated receptor alpha protects against myocardial ischaemic injury and improves endothelial vasodilatation. BMC Pharmacol. 2002;2:10.

37. Oidor-Chan VH, Hong E, Pérez-Severiano F, et al. Fenofibrate plus metformin produces cardioprotection in a type 2 diabetes and acute myocardial infarction model. PPAR Res. 2016;2016:8237264.

38. Sun B, Xie Y, Jiang J, et al. Pleiotropic effects of fenofibrate therapy on rats with hypertriglycemia. Lipids Health Dis. 2015;14:27. 